\title{
DYNAMIC VS RigID SEAT SYSTEM IN CEREBRAL PALSY: QUANTITATIVE COMPARISON
}

\author{
Avellis, M.; Cimolin, V.; PiCCinini, L.; CAZZAniGA, A.; \\ TurConi, A.C.; Crivellini, M. \& GAlli, M.
}

Abstract: High-tone extensor thrust or involuntary muscle contractions experienced by many children with Cerebral Palsy with severe dystonia, can cause a host of problems for the patients relating to the seating system. To improve postural stability the concept of a dynamic seat has been suggested as a potential solution. In this study a quantitative comparison of a dynamic seat system versus a rigid seat system in 7 dystonic patients with Cerebral Palsy, using quantitative analysis of movement (3D kinematics and pressure distribution) was conducted.

The obtained results demonstrate that the seating system in the dynamic configuration is able to reduce the forces experienced by the patients, as well as to increase the range of motion in the anterior-posterior direction, limiting the rolling down of the trunk and showing a better upper limb smoothness during the extensor thrust. This can lead to an increased occupant comfort and quality of postural stability

Key words: Dynamic seat system, dystonia, Cerebral Palsy, kinematics, pressure distribution
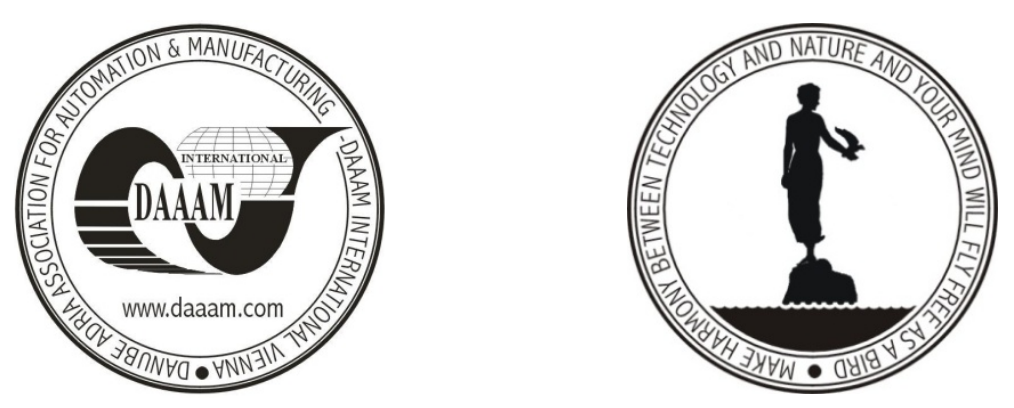

Authors' data: Dr. Avellis, M[artino]*; Dr. Cimolin, V[eronica]**; Dr. Piccinini, L[uigi] ${ }^{* * *}$;Cazzaniga, A[ndrea $]^{*}$; Dr. Turconi, A[nna] C[arla $]^{* * *}$; Prof.Crivellini, M[arcello]**; Prof. Galli, M[anuela]**, *Fumagalli srl, PIAZZA PUECHER, 2, 22037, Pontelambro, IT, **Bioeng. Dept Politecnico di Milano, via Golgi 39, 20133, Milano, IT, ***IRCCS Eugenio Medea, La Nostra Famiglia Association, via don Luigi Monza 20, 23842, Bosisio Parini, IT, a.cazzaniga@fumagalli.org, manuela.galli@polimi.it, veronica.cimolin@polimi.it

This Publication has to be referred as: Avellis, M[artino]; Cimolin, V[eronica]; Piccinini, L[uigi]; Cazzaniga, A[ndrea]; Turconi, A[nna] C[arla]; Crivellini, M[arcello] \& Galli, M[anuela] (2008). Dynamic VS Rigid Seat System in Cerebral Palsy: Quantitative Comparison, Chapter 02 in DAAAM International Scientific Book 2008, pp. 015-026, B. Katalinic (Ed.), Published by DAAAM International, ISBN 978-3-901509-66-7, ISSN 1726-9687, Vienna, Austria

DOI: $10.2507 /$ daaam.scibook.2008.02 